\title{
EDITORIAL
}

\section{GRUPOS DE TRABAJO}

Al iniciar la publicación de Enseñanza de las Ciencias, hace casi 10 años, éramos conscientes de que la investigación didáctica constituía en nuestro país un campo apenas explorado. Nuestra revista nació, más como fruto de una necesidad - eso sí, ampliamente sentida- que como expresión de una realidad ya existente. Fue, en cierto modo, un instrumento de impulso, lo que explica algunas de sus características más específicas: por ejemplo, la atención concedida a las reseñas bibliográficas, a la presentación de las revistas internacionales y, en general, todo el contenido de las secciones «Información bibliográfica y noticias» $\mathrm{y}$ «Intercambios, comentarios y críticas». Precisamente por ese carácter de inicio y de necesidad consideramos particularmente importante favorecer el conocimiento mutuo de los grupos de trabajo existentes. Creamos para ello una sección especial, en la que se han publicado breves presentaciones de muchas docenas de grupos, lo que por sí sólo es un índice del dinamismo adquirido, a lo largo de estos años, por la didáctica de las ciencias. Algunos de estos grupos han dejado de existir; otros, sin embargo, se han convertido en equipos con líneas de investigación bien establecidas y una producción ya considerable. Ha llegado, pues, el momento de presentar, con el debido detenimiento, la trayectoria de esos equipos, la problemática que han abordado, sus avances y dificultades, sus perspectivas. Estamos convencidos de que dichas presentaciones pueden ser una ayuda inestimable para todos aquellos que nos interesamos por la investigación en didáctica de las ciencias. De hecho, dos equipos se han presentado ya de esta forma: el dirigido por Dibar de Ure en la Universidad Federal Fluminense (Brasil) -ver número 8(2), pp. 140-143-y el grupo de Pessoa de Carvalho, también brasileño, de la Universidad de São Paulo, que publicamos en este mismo número (pp. 169-174). Aprovechamos esta ocasión para invitar a los equipos de investigación que cuentan ya con una cierta producción a presentar en estas páginas la recapitulación de su tarea. 